\title{
Mechanism of hif- $1 \alpha$ mediated hypoxia-induced permeability changes in bladder endothelial cells
}

\author{
C. Liu ${ }^{1}$, C.L. Shui ${ }^{2}$, Q. Wang ${ }^{3}$, H. Luo ${ }^{1}$ and C.G. Gu ${ }^{4}$ \\ ${ }^{1}$ Department of Urology, The Second People's Hospital of Deyang City, Deyang, Sichuan Province, China \\ ${ }^{2}$ Department of Anesthesiology, Affiliated Yongchuan Hospital of Chongqing Medical University, Yongchuan, Chongqing, China \\ ${ }^{3}$ Department of Pathology, Cancer Center of Guangzhou Medical University, Guangzhou, Guangdong Province, China \\ ${ }^{4}$ Department of Laboratory Medicine, The Fifth People's Hospital of Chengdu, Chengdu, Sichuan Province, China
}

\begin{abstract}
This study aimed to investigate the mechanism of hypoxia-inducible factor-1 alpha (HIF-1 $\alpha$ ) mediated hypoxia-induced permeability changes in bladder endothelial cells. Models of in vitro hypoxic cell culture of bladder cancer, bladder cancer cells with low HIF-1 $\alpha$ expression and HIF-1 $\alpha$ RNA interference (RNAi) expression vector were established. Western blot and reverse transcription polymerase chain reaction (RT-PCR) were used to detect the expression of HIF-1 $\alpha$ and vascular endothelial growth factor (VEGF) in each group. Bladder cell permeability was determined. Results showed that protein and mRNA expression of HIF- $1 \alpha$ and VEGF at 3 and $12 \mathrm{~h}$ of hypoxia were significantly higher than normal control $(\mathrm{P}<0.05)$, and peaked at $12 \mathrm{~h}$. HIF-1 $\alpha$ and VEGF expression in the hypoxic group and hypoxic $+3-\left(5^{\prime}\right.$-hydroxymethyl-2'-furyl)-1-benzyl indazole (YC-1) group were significantly higher than normal control $(P<0.05)$, while expression in the hypoxic $+Y C-1$ group was significantly lower than the hypoxic group $(P<0.05)$. Bladder cell permeability in the hypoxic and hypoxic $+Y C-1$ group were significantly increased compared to normal control $(P<0.05)$, while in the hypoxic $+Y C-1$ group was significantly decreased compared to the hypoxic group $(\mathrm{P}<0.05)$. Most of the cells in the stably transfected HIF-1 $\alpha$ RNAi expression vector pcDNA6.2GW/EmGFP-miR-siHIF-1 $\alpha$ expressed green fluorescence protein (GFP) under fluorescence microscope. pcDNA6.2-GW/ EmGFP-miR-siHIF-1 $\alpha$ could significantly inhibit HIF-1 $\alpha$ gene expression $(\mathrm{P}<0.05)$. HIF-1 $\alpha$ and VEGF expression in the hypoxic group and siHIF-1 $\alpha$ hypoxic group were significantly higher than normal group $(\mathrm{P}<0.05)$, while expression in the siHIF-1 $\alpha$ hypoxic group was significantly lower than the hypoxic group $(P<0.05)$. Findings suggest that $H I F-1 \alpha$ is an important factor in the increase of bladder cancer cell permeability.
\end{abstract}

Key words: Bladder cancer; Hypoxia inducible factor-1 $\alpha$; VEGF; Cell permeability; YC-1

\section{Introduction}

Bladder cancer is the most common malignancy of the urinary tract, having a high incidence rate and a recurrence rate above $80 \%$. Patients not only have to bear the burden of high medical expenses, but also the stress of psychological distress caused by relapses. Non-muscle invasive bladder cancer (NMIBC) comprises about $70 \%$ of all newly diagnosed bladder cancers. NMIBC tumor stages include papillary lesions that have not invaded sub-mucosal lamina propria (Ta), papillary lesions that have invaded the lamina propria but not the muscle (T1), and carcinoma in situ (CIS). At present, transurethral resection followed by instillation of adjuvant intravesical chemotherapy has been the main treatment of choice for NMIBC. However, NMIBC still has a recurrence rate of $70-80 \%(1,2)$.

Tumor cells regulate and adapt to the hypoxic environment by initiating a series of hypoxic adaptive responses. A number of studies reported that hypoxia-inducible factor-1 (HIF-1) is the central mediator of adaptive responses to hypoxia in tumors. HIF-1 is a heterodimer transcription factor consisting of $\alpha$ and $\beta$ subunits. Among these, HIF-1 $\alpha$ determines the activity of HIF-1 and is the sole oxygen regulator. HIF-1 can adapt to hypoxia by regulating the expression of various target genes and involves in the process of tumor growth, invasion and metastasis (3). HIF$1 \alpha$ has been found to be highly expressed in a variety of malignant tumors and precancerous lesions, indicating that it is closely related with tumor angiogenesis, invasion and metastasis (4).

The synthetic compound hypoxic + 3-(5'-hydroxymethyl-2'-furyl)-1-benzyl indazole (YC-1) has superior anti-angiogenic and anti-tumor activities. YC-1 was first discovered by Ko et al. (5), who reported that its role is achieved by activating platelet soluble guanylate cyclase and upregulation of adenosine monophosphate and cyclic

Correspondence: C.G. Gu: <guchangguo@sina.com> 
guanosine monophosphate. Vascular endothelial growth factor (VEGF), also known as vascular permeability factor, is an efficient and specific growth factor for vascular endothelial cells. It has a strong effect on promoting mitosis and chemotaxis of vascular endothelial cells, stimulating angiogenesis, and increasing vascular permeability. In normal tissue, its expression is very low or absent, but it is highly expressed in malignant solid tumors and positively correlated with the malignancy grade of the tumor (6). This paper describes for the first time the role of HIF-1 $\alpha /$ VEGF in cancer.

This study aimed to investigate the role of HIF in the recurrence of bladder cancer at the gene level, in order to provide a new therapeutic approach for the disease. We hypothesized that during hypoxia, an increase in the HIF- $1 \alpha$ and VEGF protein expression would lead to an increase in bladder cancer cell permeability, and that HIF$1 \alpha$ is an important factor in the increase of bladder cancer cell permeability.

\section{Material and Methods}

Experiments were performed at the Central Laboratory of the Affiliated Yongchuan Hospital of Chongqing Medical University and Department of Pathology, Cancer Center of Guangzhou Medical University. Cells collection period were from February 2015 to February 2016.

All procedures were approved by the Ethics Committee of The Second People's Hospital of Deyang City, Sichuan, China (Reference number [2014]-20) and in accordance with the 1964 Helsinki declaration and its later amendments or comparable ethical standards.

\section{Material}

Cell lines. Bladder cancer cells were purchased from Cell Bank of the Chinese Academy of Sciences (Shanghai, China).

Main reagents and instruments. Rabbit HIF- $1 \alpha$ polyclonal antibodies (Upstate Biotechnology, USA); VEGF polyclonal antibodies, albumin-fluorescein isothiocyanate conjugate (FITC-albumin), $\beta$-actin monoclonal antibodies (Sigma-Aldrich Corporation, USA); IgG secondary antibodies (Beijing Zhongshan Gold Bridge Biotechnology Corporation Ltd, China); newborn calf serum (Chengdu Harry Biotechnology Corporation Ltd, China); primer synthesis (Sangon Biotechnology (Shanghai) Corporation Limited, China); Roswell Park Memorial Institute (RPMI) 1640 culture medium (HyClone Laboratories, USA); Bicinchoninic acid (BCA) protein assay kit (Pierce ${ }^{\mathrm{TM}}$, Thermo Fisher Scientific, USA); Mini Trans-Blot ${ }^{B}$ electro transfer system, fluorescence quantitative PCR instrument, ChemiDoc XRS Gel Analysis System, "Quantity one" software (Bio-Rad Laboratories, USA); Milicell ${ }^{\mathrm{TM}}$ electrical resistance system (ERS) instrument (Millipore, USA); inverted fluorescence microscope model TH4-200 (Olympus Corporation, Japan); ultra-sensitive enhanced chemiluminescence (ECL) kit
(Pierce Biotechnology, USA); Heraeus $\mathrm{CO}_{2}$ constant temperature incubator (Heraeus, Germany); DU ${ }^{\mathbb{B}}-640$ ultraviolet spectrophotometer (Beckman Inc., USA); modular incubator chamber (Billups-Rothenberg Inc., USA).

\section{Methods}

Model of in vitro hypoxic cell culture of bladder cancer. Bladder cancer cells were cultured in a culture flask with primary culture medium and kept at $37^{\circ} \mathrm{C}$ in a $5 \% \mathrm{CO}_{2}$ incubator. The culture medium was replaced every 2 days. When the cell culture reached around $90 \%$ confluence, it was digested with $0.25 \%$ trypsin- $0.01 \%$ ethylenediaminetetraacetic acid (EDTA) solution and subcultured. Cells were then seeded at a concentration of $1.5 \times 10^{5} / \mathrm{cm}^{2}$ in a $0.1 \%$ gelatin-coated Transwell ${ }^{\mathrm{TM}}$ polycarbonate membrane. Culture medium was replaced every 2 days after $24 \mathrm{~h}$ of inoculation. The transendothelial electrical resistance (TER) of the monolayer endothelial cells was measured with Milicell $^{\mathrm{TM}}$ ERS for cell integrity. When the TERs were stable, we proceeded to the next step of experiment. Cells seeded in the 6-well plates were examined and placed in a hypoxic tank filled with $1 \% \mathrm{O}_{2}$ of mixed gas $\left(94 \% \mathrm{~N}_{2}, 5 \% \mathrm{CO}_{2}, 1 \% \mathrm{O}_{2}\right)$ and cultured in a $37^{\circ} \mathrm{C}$ cell culture incubator. Observation was done at 0,3 , and $12 \mathrm{~h}$ post-hypoxia.

Model of hypoxic HIF-1 $\alpha$ inhibitor. After the bladder cancer cells in the 6-well plate reached complete confluence or the monolayer bladder cancer cells in the Transwell ${ }^{\mathrm{TM}}$ had been tested for TER stabilization, these were randomly assigned into normal control group (normal culture under normoxia with $5 \% \quad \mathrm{CO}_{2}$ and $\mathrm{O}_{2}$ in air), hypoxic group (cultured in $1 \% \mathrm{O}_{2}$ for $6 \mathrm{~h}$ ) and hypoxic + 3(5'-hydroxymethyl-2'-furyl)-1-benzyl indazole (YC-1) group

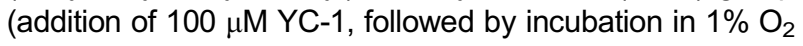
for $6 \mathrm{~h}$ ). Time of incubation with YC-1 was $48 \mathrm{~h}$.

Model of HIF-1 $\alpha$ RNA interference (RNAi) expression vector. RNAi expression vector was established. Amplification of recombinant plasmid and DNA extraction, plasmid transfection, screening of SiHIF- $1 \alpha$ positive cell clones and identification of pcDNA6.2-GW/EmGFP-miR-siHIF-1 $\alpha$ stable expression cell lines were performed.

HIF-1 $\alpha$ and VEGF protein expression (by western blot). Cells from each group were treated with cell lysate, lysed for $30 \mathrm{~min}$ and centrifuged at 8,000-10,000 $\mathrm{g}$ for $10 \mathrm{~min}$ at $4^{\circ} \mathrm{C}$. The supernatant was carefully extracted for total protein concentration, which was determined according to the BCA kit instructions. This was followed by protein denaturation, sample uploading, sodium dodecyl benzene sulfonate (SDBS) gel electrophoresis for 1-2 h and wet transfer for $30-50 \mathrm{~min}$. This was then incubated with rabbit HIF- $1 \alpha$ and VEGF polyclonal antibodies at $4^{\circ} \mathrm{C}$ overnight and IgG secondary antibodies at room temperature for 1-2 $\mathrm{h}$. Following this, ECL exposure solution was added and exposure was done under the gel imaging system. "Quantity one" software was used to analyze the gray scale value of each antibody strip. 
HIF-1 $\alpha$ and VEGF mRNA expression (detected with $R T-P C R$ ). RNA was extracted with TRIzon, followed by reverse transcription and detection with RT-PCR. Expression ratio and relative content of the HIF- $1 \alpha$, VEGF mRNA and internal reference ( $\beta$-actin) was calculated. Primers used were as follows: HIF- $1 \alpha-F$ : TCAAAGTCGGACAGC CTCA, HIF-1 $\alpha$-R: CCCTGCAGTAGGTTTCTGCT; VEGFF: GAAGTGGTGAAGTTCATGGATGTC, VEGF-R: CGAT CGTTCTGTATCAGTCTTTCC; $\beta$-actin-F: TGAGACCTTC AACACCCCAG, $\beta$-actin-R: GCCATCTCTTGCTCGAAGTC.

Determination of bladder cancer cell permeability. Culture medium was discarded. FITC-albumin $(100 \mu \mathrm{L}$, $1 \mathrm{mg} / \mathrm{mL}$ dissolved in D-Hank solution) was added to the upper part of the double-chamber, while $500 \mu \mathrm{L}$ $\mathrm{D}-$ Hank solution was added to the lower part at $37^{\circ} \mathrm{C}$. Then, the culture plate was placed back into the incubator and continued to culture for $1 \mathrm{~h}$. Following this, the solutions from the upper and lower chambers were sucked out.

The excitation and emission wavelength of the fluorescence spectrophotometer were set at 490 and $525 \mathrm{~nm}$, respectively. Fluorescence intensity of each sample was determined to analyze permeability changes.

\section{Statistical analysis}

Data are reported as means $\pm S D$. Analysis was performed using SPSS 19.0 statistical software (SPSS Inc., USA). Comparison between groups were performed with ANOVA test. $\mathrm{P}<0.05$ was considered statistically significant.

\section{Results}

\section{Effects of hypoxia on HIF-1 $\alpha$ and VEGF expression in bladder endothelial cells}

Compared with the normal control group, the protein and mRNA expression of HIF- $1 \alpha$ and VEGF were significantly higher at 3 and $12 \mathrm{~h}$ of hypoxia, and peaked at 12 h $(P<0.05$; Figure $1 \mathrm{~A}-\mathrm{C})$.

\section{YC-1 reduced the protein and mRNA expression of HIF-1 $\alpha$ and VEGF expression}

Protein and mRNA expression of HIF- $1 \alpha$ and VEGF in the hypoxic group and hypoxic $+\mathrm{YC}-1$ group were significantly higher than the normal control group $(P<0.05)$, while expression in the hypoxic $+\mathrm{YC}-1$ was significantly lower than the hypoxic group $(P<0.05$; Figure $2 A-C)$. Protein and mRNA expression of HIF-1 $\alpha$ and VEGF were significantly reduced by $\mathrm{YC}-1$ (Figure $2 \mathrm{~B}$ and $\mathrm{C}$ ).

\section{Bladder cancer cell permeability}

Cell permeability in the hypoxic group and hypoxic + YC-1 group were significantly increased compared to the normal control group $(P<0.05)$, while in the hypoxic + YC-1 group, it was significantly decreased compared to the hypoxic group $(\mathrm{P}<0.05$; Figure 3$)$.
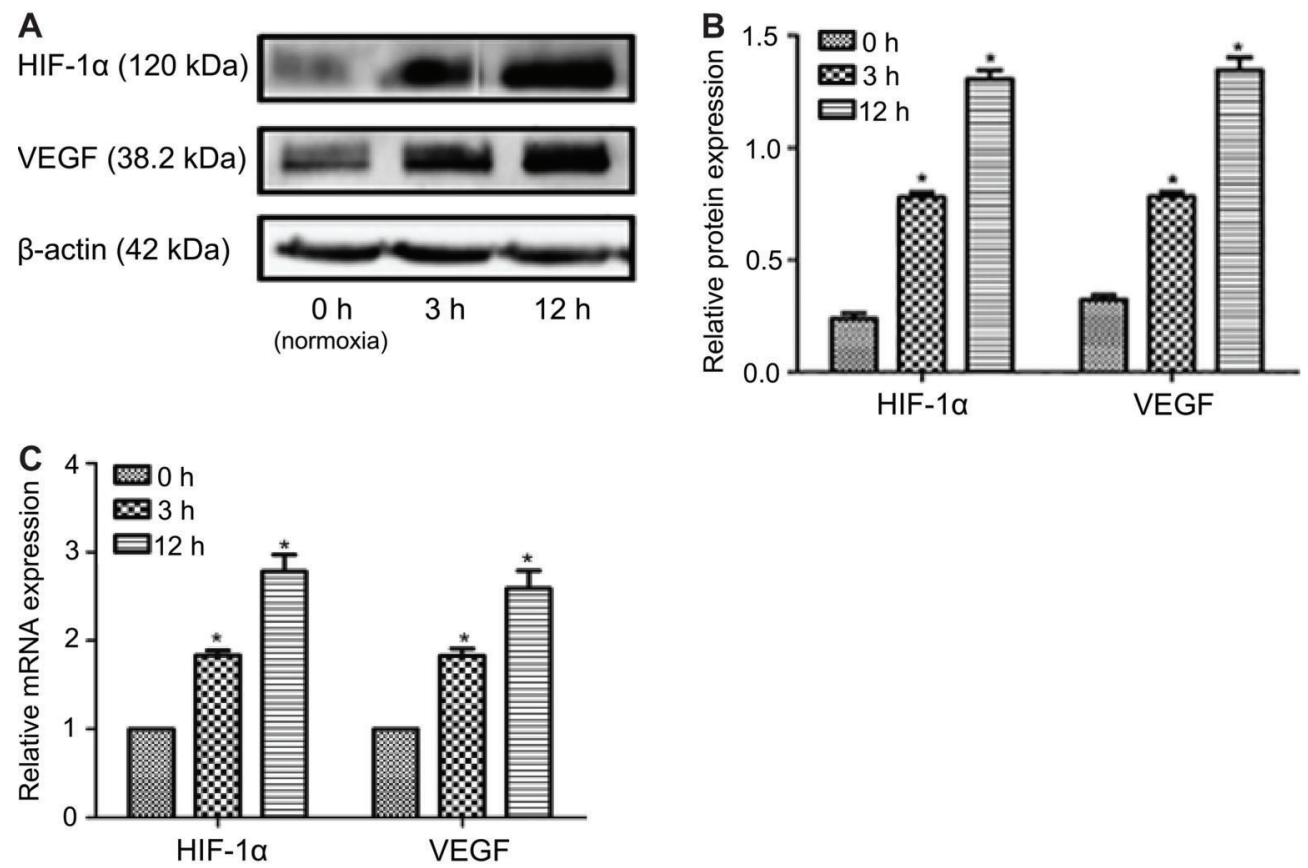

Figure 1. $A$, HIF-1 $\alpha$ and VEGF protein expression. $B$, Histogram of HIF-1 $\alpha$ and VEGF protein expression. $C$, Histogram of HIF- $1 \alpha$ and VEGF mRNA expression. Data are reported as means $\pm S D$. ${ }^{*} \mathrm{P}<0.05$ compared with normal control group (ANOVA). 

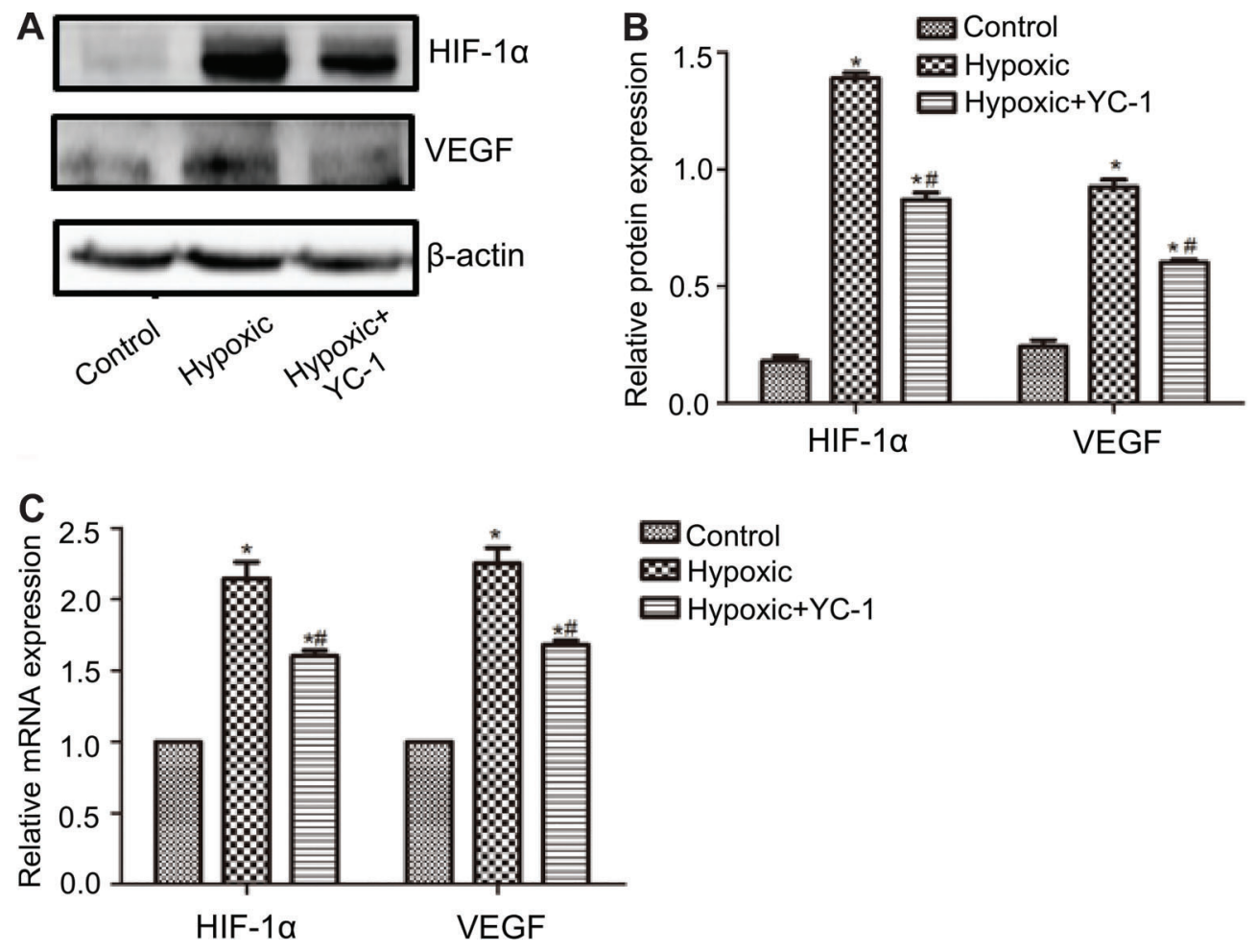

Figure 2. $A$, HIF-1 $\alpha$ and VEGF expression. $B$, Histogram of HIF-1 $\alpha$ and VEGF protein expression. $C$, Histogram of HIF-1 $\alpha$ and VEGF mRNA expression. Data are reported as means $\pm \mathrm{SD}$. ${ }^{*} \mathrm{P}<0.05$ compared with normal control group; ${ }^{*} \mathrm{P}<0.05$ compared with hypoxic group (ANOVA). Time of incubation with $\mathrm{YC}-1=48 \mathrm{~h}$.

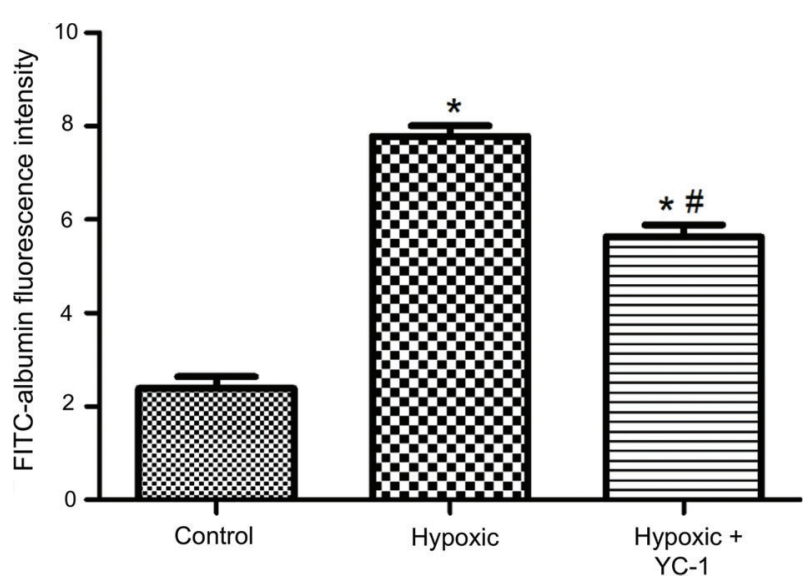

Figure 3. Effect of YC-1 on increased bladder cancer cell permeability by hypoxia. Data are reported as means $\pm \mathrm{SD}$. ${ }^{*} \mathrm{P}<0.05$ compared with normal control group; ${ }^{\#} \mathrm{P}<0.05$ compared with hypoxic group (ANOVA). Time of incubation with $\mathrm{YC}-1=48 \mathrm{~h}$.

\section{Effects of HIF-1 $\alpha$ RNAi expression vector on VEGF expression and bladder cancer cell permeability}

Most of the cells in the stably transfected HIF- $1 \alpha$ RNAi expression vector pcDNA6.2-GW/EmGFP-miR-siHIF-1 $\alpha$ expressed green florescence protein (GFP) (Figure 4A).
This vector could significantly inhibit HIF-1 $\alpha$ gene expression $(P<0.05$; Figure $4 B$ and $C)$.

\section{Effects of stable transfection on HIF-1 $\alpha$ and VEGF expression}

The HIF- $1 \alpha$ and VEGF expression in the hypoxic group and siHIF-1 $\alpha$ hypoxic group was significantly higher $(P<0.05)$ than the normal control group (Figure $5 A)$. The protein (Figure $5 B$ ) and mRNA expression (Figure $5 C$ ) in the siHIF- $1 \alpha$ hypoxic group were significantly lower than the hypoxic group $(P<0.05)$.

\section{Discussion}

Bladder cancer is one of the most common urologic cancer with high incidence rate. During development, many solid tumors loose regulation of cell proliferation and apoptosis. This accelerates its growth, and when growth rate is higher than the process of angiogenesis, local ischemia and hypoxia of the tumor can occur.

HIF-1a was first discovered by Semenza et al. (7) in 1992. A large number of studies showed that HIF-1 $\alpha$, which has long been recognized as one of the important transcription factor that mediate cellular response to hypoxia, plays an important role in the regulation of pathophysiological changes in ischemic and hypoxic conditions (8). 


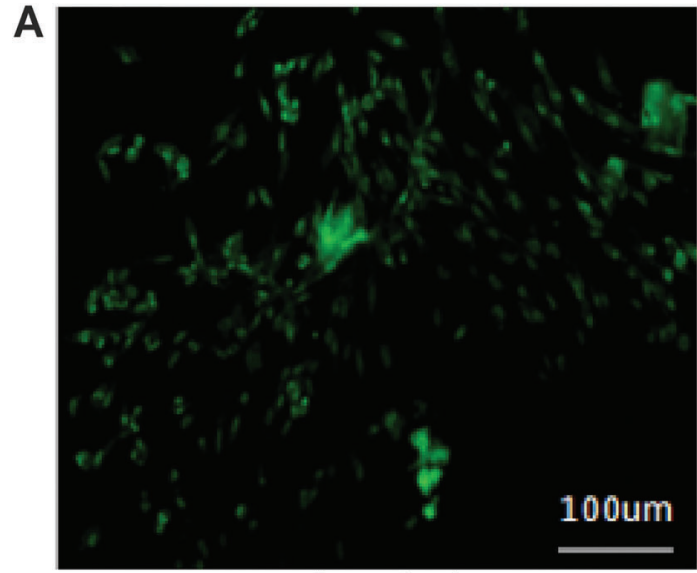

normal control group

B

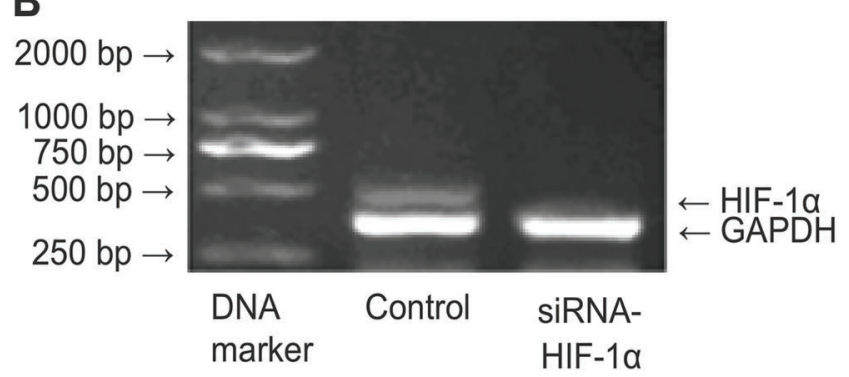

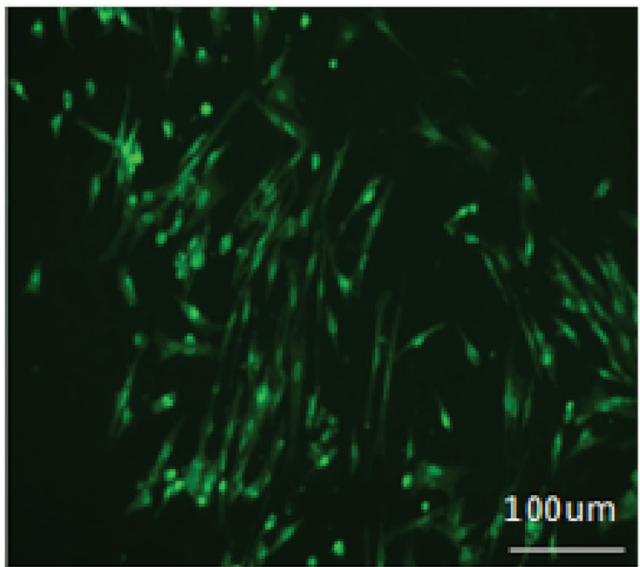

hypoxic group

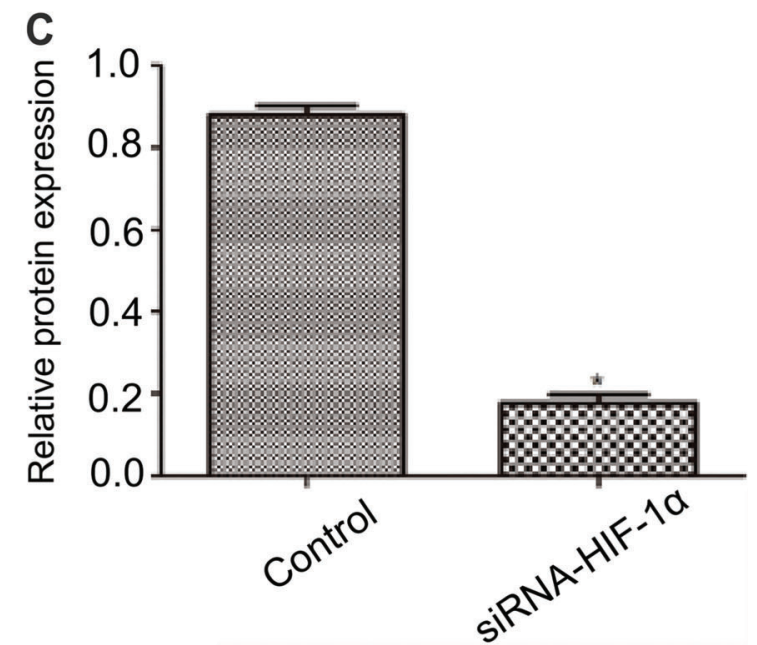

Figure 4. Effects of HIF-1 $\alpha$ RNAi expression vector on VEGF expression and bladder cancer cell permeability. $A$, Stably transfected HIF-1 $\alpha$ RNAi expression vector in normal control group and hypoxic group. $B, \mathrm{HIF}-1 \alpha$ gene expression after stable transfection of HIF- $1 \alpha$ RNAi expression vector pcDNA6.2-GW/EmGFP-miR-siHIF-1 $\alpha$. C, Histogram of HIF-1 $\alpha$ gene expression after stable transfection of HIF-1 $\alpha$ RNAi expression vector pcDNA6.2-GW/EmGFP-miR-siHIF-1 $\alpha$. Data are reported as means \pm SD. ${ }^{*} \mathrm{P}<0.05$ compared with normal control group (ANOVA). GADPH: glyceraldehyde 3-phosphate dehydrogenase.

The expression of HIF-1 is subjected to hypoxia, tumor genes and various regulatory factors, and is an important factor in hypoxia-induced adaptive gene expression.

HIF-1 is composed of two subunits, the HIF-1 $\alpha$ and HIF-1 $\beta$ subunits. The intracellular protein level of the HIF$1 \beta$ subunits is not affected by the level of oxygenation while the HIF- $1 \alpha$ gene is subjected to the regulation of hypoxia signals. Under normoxic conditions, the $\alpha$ subunit undergoes post-translational modifications and $\mathrm{O}_{2}$-dependent prolyl hydroxylation, and is degraded via the ubiquitinproteasome pathway mediated by $\mathrm{PVHL}$ (von Hippel-Lindau tumor suppressor protein). In hypoxic condition, HIF-1 $\alpha$ does not undergo self-hydroxylation and degradation, and thus it is stable. It forms a transcriptionally active heterodimer complex with the HIF-1 $\beta$ subunit and binds to the hypoxia-response element of the target genes. It involves the regulation of adaptive response to hypoxia through a variety of target gene expressions (9-11). YC-1 is a specific inhibitor of HIF- $1 \alpha$. It can reduce the accumulation of HIF-1 $\alpha$ and inhibit HIF-1 transcriptional activity through a pathway that is independent of soluble guanylate cyclase (12). It can also promote protein degradation of $\mathrm{HIF}-1 \alpha$ (13).

Vascular endothelium is the inner lining of blood vessels with semi-selective permeable membrane. Endothelial cells regulate the tension of the blood vessel, maintain their normal structure, secrete fibrinolytic protein, anticoagulant and other substances, and have anti-inflammatory effects (14). Recent studies have confirmed that there are many factors involved in the whole process of angiogenesis in 

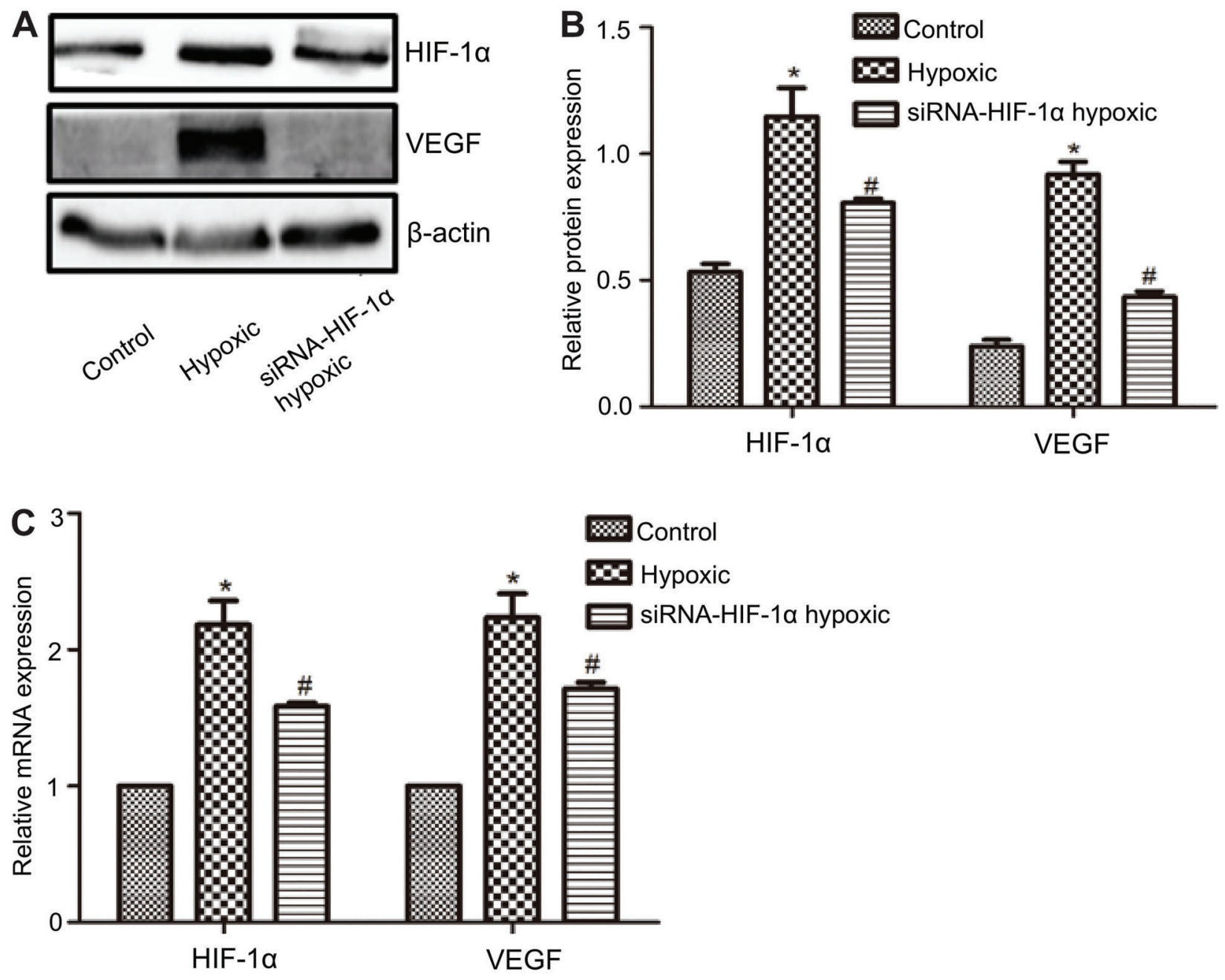

Figure 5. Effects on HIF-1 $\alpha$ and VEGF expression after stable transfection. $A, \mathrm{HIF}-1 \alpha$ and VEGF expression. $B$, Histogram of HIF-1 $\alpha$ and VEGF protein expression. $C$, Histogram of HIF-1 $\alpha$ and VEGF mRNA expression. Data are reported as means $\pm S D$. ${ }^{*} P<0.05$ compared with normal control group; ${ }^{\#} \mathrm{P}<0.05$ compared with hypoxic group (ANOVA).

solid tumors. Among these, VEGF is known to be the most active and the most specific angiogenesis inducing factor. The increase of HIF- $1 \alpha$ and VEGF were parallel, indicating a correlation between the two. Thus, it is speculated that $\mathrm{HIF}-1 \alpha$ may stimulate angiogenesis by increasing the expression of VEGF to adapt to the growth environment of hypoxic and low-sugar content, so that the tumor can continue to grow and metastasize distantly (15).

A number of studies has identified high expression of HIF-1 $\alpha$ in gastric cancer and various other cancers, and it is found to be closely associated with the biological behavior of tumors $(16,17)$. HIF- $1 \alpha$ shows high expression in hypoxic environment. This stimulates the release of VEGF in tumor cells and promotes angiogenesis $(18,19)$.

RNAi can silence the expression of target genes. It can specifically knock down or turn off the expression of a specific gene, participate in the protection of genome against invasion and thus maintain the genome stability. This is a technique of reverse genetics, which plays an important role in functional genomics research (20-25).

In the first part of this study, a model of in vitro hypoxic cell culture of bladder cancer was established. We preliminarily postulated that increase in $\mathrm{HIF}-1 \alpha$ and VEGF expression is one of the mechanisms that leads to the increase of cell permeability in hypoxia. In the second part of the study, an HIF-1 $\alpha$ inhibitor YC-1 was added and we found that a decrease in the HIF- $1 \alpha$ expression resulted in a decrease in VEGF expression and an increase in the permeability of bladder cancer cells during hypoxia. To further clarify whether the activation of HIF- $1 \alpha$ was involved in the increase of bladder cancer cells permeability during hypoxia, we used an established bladder cancer cell model with low HIF-1 expression to study the changes of tumor cell permeability in hypoxia. 
This study finally found that hypoxia induced an increase in bladder cancer cell permeability. HIF-1 $\alpha$ inhibitor YC-1 and HIF-1 $\alpha$ RNAi could significantly inhibit the increase of hypoxia-induced cell permeability. HIF-1 $\alpha$ is an important factor in the increase of bladder cancer cell permeability.

\section{References}

1. Anastasiadis A, de Reijke TM. Best practice in the treatment of nonmuscle invasive bladder cancer. Ther Adv Urol 2012; 4: 13-32, doi: 10.1177/1756287211431976.

2. Nepple KG, O'Donnell MA. The optimal management of T1 high-grade bladder cancer. Can Urol Assoc J 2009; 3: S188-S192, doi: 10.5489/cuaj.1194.

3. Masoud GN, Li W. HIF-1 $\alpha$ pathway: role, regulation and intervention for cancer therapy. Acta Pharm Sin B 2015; 5: 378-389, doi: 10.1016/j.apsb.2015.05.007.

4. Jubb AM, Pham TQ, Hanby AM, Frantz GD, Peale FV, Wu TD, et al. Expression of vascular endothelial growth factor, hypoxia inducible factor 1 alpha, and carbonic anhydrase IX in human tumours. J Clin Pathol 2004; 57: 504-512, doi: 10.1136/jcp.2003.012963.

5. Ko FN, Wu CC, Kou SC, Lee FY, Teng CM. YC-1, a novel activator of platelet guanylate cyclase. Blood 1994; 84: 4226-4233.

6. Bussolati B, Mason JC. Dual role of VEGF-induced hemeoxygenase-1 in angiogenesis. Antioxid Redox Signal 2006; 8: 1153-1163, doi: 10.1089/ars.2006.8.1153.

7. Semenza GL, Agani F, Booth G, Forsythe J, lyer N, Jiang $\mathrm{BH}$, et al. Structural and functional analysis of hypoxiainducible factor 1. Kidney Int 1997; 51: 553-555, doi: 10.1038/ ki.1997.77.

8. Semenza G. Signal transduction to hypoxia-inducible factor 1. Biochem Pharmacol 2002; 64: 993-998, doi: 10.1016/S00062952(02)01168-1.

9. Semenza GL. HIF-1 and mechanisms of hypoxia sensing. Curr Opin Cell Biol 2001; 13: 167-171, doi: 10.1016/S09550674(00)00194-0.

10. Cummins EP, Taylor CT. Hypoxia-responsive transcription factors. Pflügers Arch 2005; 450: 363-371, doi: 10.1007/ s00424-005-1413-7.

11. Semenza GL. Life with oxygen. Science 2007; 318: 62-64, doi: 10.1126/science.1147949.

12. Chun YS, Yeo EJ, Choi E, Teng CM, Bae JM, Kim MS, et al. Inhibitory effect of YC-1 on the hypoxic induction of erythropoietin and vascular endothelial growth factor in Hep3B cells. Biochem Pharmacol 2001; 61: 947-954, doi: 10.1016/ S0006-2952(01)00564-0.

13. Kim HL, Yeo EJ, Chun YS, Park JW. A domain responsible for HIF-1alpha degradation by YC-1, a novel anticancer agent. Int J Oncol 2006; 29: 255-260, doi: 10.3892/ijo.29.1.255.

14. Mullin JM, Agostino N, Rendon-Huerta E, Thornton JJ. Keynote review: epithelial and endothelial barriers in human

\section{Acknowledgements}

This study was supported by the Deyang City Science and Technology Bureau Support Plan (Project No. 2017 SZ097-1).

disease. Drug Discov Today 2005; 10: 395-408, doi: 10.1016/ S1359-6446(05)03379-9.

15. Maslennikova AV, Orlova AG, Prianikova TI, Kostenikov NA, Vinogradova luN, Denisenko AN. Clinical significance of and diagnostic methods for tumoral hypoxia. Vopr Onkol 2011; 57: 413-420.

16. Huang $C$, Sun $Z$, Sun $Y$, Chen $X$, Zhu X, Fan $C$, et al. Association of increased ligand cyclophilin $A$ and receptor CD147 with hypoxia, angiogenesis, metastasis and prognosis of tongue squamous cell carcinoma. Histopathology 2012; 60: 793-803, doi: 10.1111/j.1365-2559.2011.04130.x.

17. Horiuchi A, Hayashi T, Kikuchi N, Hayashi A, Fuseya C, Shiozawa $\mathrm{T}$, et al. Hypoxia upregulates ovarian cancer invasiveness via the binding of HIF- $1 \alpha$ to a hypoxia-induced, methylation-free hypoxia response element of S100A4 gene. Int J Cancer 2012; 131: 1755-1767, doi: 10.1002/ijc.27448.

18. Huang X, He Z, Jiang X, Hou M, Tang Z, Zhen X, et al. Folic acid represses hypoxia-induced inflammation in THP-1 cells through inhibition of the PI3K/Akt/HIF-1 $\alpha$ pathway. PLoS One 2016; 11: e0151553, doi: 10.1371/journal.pone.0151553.

19. Zhang $\mathrm{HZ}$, Zhao JH, Zhao XH, Zhu SC, Liu B. Effect of hypoxia on HIF- $1 \alpha$ and VEGF expression and radiosensitivity in esophageal cancer cell line Eca109. J Hebei Med Univ 2008; 29: 815-818.

20. Fire A, Xu S, Montgomery MK, Kostas SA, Driver SE, Mello CC. Potent and specific genetic interference by doublestranded RNA in Caenorhabditis elegans. Nature 1998; 391: 806-811, doi: $10.1038 / 35888$.

21. Meister G, Tuschl T. Mechanisms of gene silencing by doublestranded RNA. Nature 2004; 431: 343-349, doi: 10.1038/ nature02873.

22. Matzke MA, Birchler JA. RNAi-mediated pathways in the nucleus. Nat Rev Genet 2005; 6: 24-35, doi: 10.1038/ nrg1500.

23. Lage $\mathrm{H}$. Therapeutic potential of RNA interference in drugresistant cancers. Future Oncol 2009; 5: 169-185, doi: 10.2217/14796694.5.2.169.

24. Bobbin ML, Rossi JJ. RNA interference (RNAi)-based therapeutics: delivering on the promise? Annu Rev Pharmacol Toxicol 2016; 56: 103-122, doi: 10.1146/annurev-pharmtox010715-103633.

25. Mamta, Reddy KR, Rajam MV. Targeting chitinase gene of Helicoverpa armigera by host-induced RNA interference confers insect resistance in tobacco and tomato. Plant Mol Biol 2016; 90: 281-291, doi: 10.1007/s11103-015-0414-y. 